\title{
Duas novas espécies de Ablaptus Stål (Heteroptera, Pentatomidae, Discocephalinae) ${ }^{1}$
}

\author{
Jocélia Grazia ${ }^{2}$ \\ Adriana Zwetsch ${ }^{2}$
}

\begin{abstract}
Two new species of Ablaptus Stål (Heteroptera, Pentatomidae, Discocephalinae). Two new species of Ablaptus Stål, 1864 are described and illustrated: A. costaricensis sp.n. and A. phoenix sp.n., both from Costa Rica. The female genitalia of A. brevirostrum Rolston, 1988 is described and key to the species of Ablaptus Stål, 1864 (only for females) is presented.

KEY WORDS. Pentatomidae, Discocephalini, Ablaptus, female genitalia, new species.
\end{abstract}

O gênero Ablaptus Stål, 1864 foi proposto para A. amazonus Stål, 1864. Rolston (1988) incluiu duas novas espécies: A. brevirostrum e A. tavakiliani.

BECKER \& GRAZIA (1989) adicionaram três novas espécies: A. bolivianus, A. lopesi e A. simillimus; BECKER \& GRAZIA (1997) propuseram uma nova combinação e uma nova sinonimia ao compararem os holótipos de Pentatoma varicornis Walker, 1867 e $A$. lopesi considerando esta última um sinônimo júnior de $P$. varicornis. A disponibilidade de exemplares fêmeas provenientes da Costa Rica possibilitou a descrição de duas novas espécies que pelo aspecto geral se assemelham a $A$. brevirostrum, porém a forma das placas genitais distingue facilmente estas três espécies; o parátipo fềmea de $A$. brevirostrum foi examinado e a genitália descrita e ilustrada.

A dissecação, tratamento, ilustrações e nomenclatura da genitália seguem BECKER \& GRAZIA (1989). As medidas estão expressas em milímetros. O material examinado pertence à coleção do INBio - Instituto Nacional de Biodiversidad, Santo Domingo, Heredia, Costa Rica. Agradecemos o empréstimo ao Dr. J.A.U. Gómez.

\section{Ablaptus costaricensis sp.n.}

Figs 1-2

Descrição. Forma oval, bastante convexa em especial na face ventral. Coloração de fundo castanho-avermelhada, pontuação ferrugínea grosseira e densa.

Cabeça, diante dos olhos, de contorno sub-retangular, mais larga do que longa, declivosa. Margens externas das jugas sinuosas, convergentes no ápice e

1) Contribuição número 360 do Departamento de Zoologia da Universidade Federal do Rio Grande do Sul.

2) Departamento de Zoologia, Universidade Federal do Rio Grande do Sul. Avenida Paulo Gama, 90046-900 Porto Alegre, Rio Grande do Sul, Brasil. Bolsista CNPq.

E-mail: jocelia@vortex.ufrgs.br 


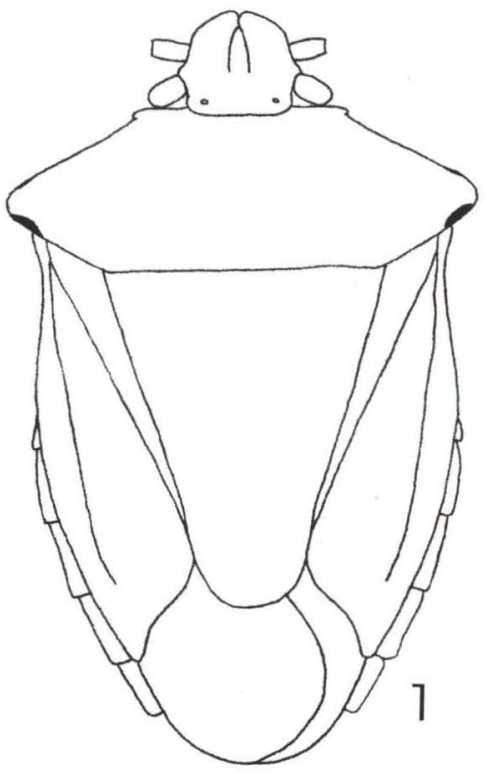

$1 \mathrm{~mm}$

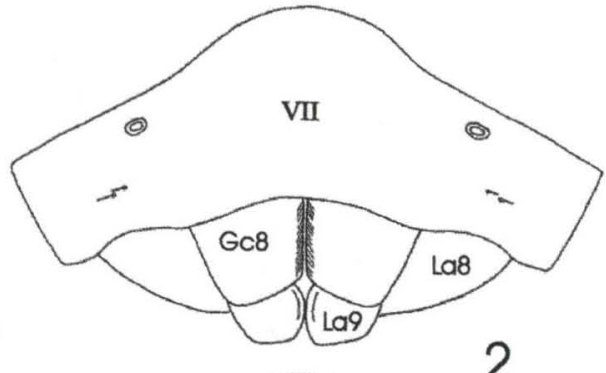

2

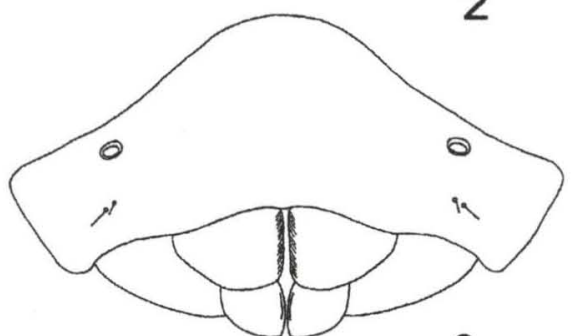

3

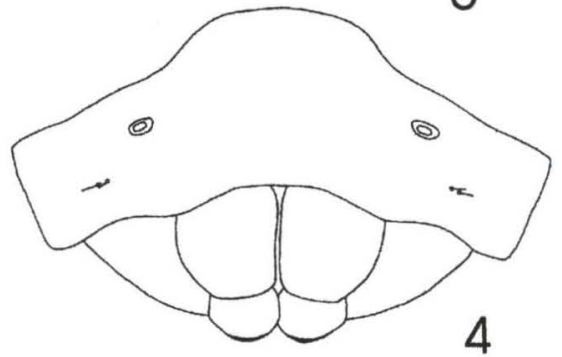

$1 \mathrm{~mm}$

Figs 1-4. (1) Ablaptus costaricensis fêmea, dorsal; (2-4) placas genitais da fêmea, ventral: (2) Ablaptus costaricensis sp. n.; (3) Ablaptus phoenix sp.n.; (4) Ablaptus brevirostrum (Parátipo). (Gc8) Gonocoxitos 8, (La8) laterotergitos 8, (La 9) laterotergitos 9, (VII) sétimo urosternito. Escala $1 \mathrm{~mm}=3,2 \mathrm{~cm}$.

sobrepostas na frente do clípeo. Tubérculos anteníferos encobertos pelas jugas, não visíveis em vista dorsal. Rostro ultrapassando, em muito, o limite anterior do terceiro segmento abdominal; primeiro artículo com cerca da metade basal contida nas búculas, atingindo o $1 / 3$ anterior do prosterno; segundo artículo comprimido lateralmente, alcançando as mesocoxas; terceiro e quarto artículos comprimidos dorsoventralmente, o terceiro alcançando as metacoxas.

Pronoto. Margem anterior rasamente convexa, dentículos nos ângulos ântero-laterais em pontas rombas; $2 / 3$ anteriores acentuadamente em declive, densamente pontuado; coloração de fundo castanho-avermelhada, com pontuações grandes, ferrugineas, freqüentemente confluentes nas margens ântero-laterais. Ângulos umerais rombos projetados lateralmente formando um ângulo inferior a $90^{\circ}$. Escutelo: 
coloração e pontuações como no pronoto, margens laterais sub-retilíneas, disco elevado, ápice uniformemente arredondado, margens laterais não refletidas; fóveas dos ângulos basais obsoletas. Hemiélitros: coloração castanha com manchas amplas avermelhadas no endocório, pontuações ferrugíneas do cório mais confluentes que no pronoto e escutelo. Ápice do cório alcançando o meio do sétimo segmento do conexivo. Membrana mal ultrapassando o ápice do abdome. Pernas amarelo-escuras com pontuações densas e grosseiras nos fêmures e tíbias. Conexivo estreitamente exposto, coloração castanho-avermelhada e pontuações similares às do cório, borda preta interrompida próxima ao ângulo póstero-lateral de cada segmento. Abdome castanho-avermelhado na face ventral e com pontuações castanhas, mais finas e concentradas nos terços laterais; 1/3 médio com pontuações mais grosseiras e mais esparsas. Espiráculos negros; tricobótrios localizados externamente à linha imaginária que tangencia os espiráculos.

Medidas. Comprimento da cabeça 2,46; largura da cabeça 3,77; comprimento diante dos olhos 1,14; distância interocular 2,29; comprimento dos artículos antenais I 0,98 , II 1,31 , III 1,55 , IV 2,54, V 2,46; comprimento do pronoto 3,52; largura do pronoto 9,26; comprimento do escutelo 6,72; largura do escutelo 5,65; largura abdominal 8,69; comprimento do cório 8,61.

Genitália. Margem posterior do sétimo urosternito (VII) côncava, sinuosa sobre os laterotergitos 8 ( $\mathrm{La} 8$ ) e gonocoxitos 8 (Gc8). Gonocoxitos 8 subquadrangulares; ângulo apical do bordo posterior confluindo com a base da margem lateral externa dos laterotergitos 9 (La9) e o ápice da margem lateral interna do laterotergito 8. Laterotergitos 8 destituídos de espiráculos, bordo posterior uniformemente convexo. Laterotergitos 9 recobrindo o segmento $\mathrm{X}$, com bordo posterior subtruncado, margens laterais internas convexas, adjacentes medianamente, com uma prega submarginal nos $2 / 3$ basais. Genitália interna não dissecada por tratar-se de apenas um exemplar.

Material-tipo. Holótipo fêmea. CosTA Rica, Sirena: Corcovado Nat. PK., Osa Penin., 14.VIII.1980, D.H. Janzen \& W. Hallwachs col. (nº INBio CRI001715614).

\section{Ablaptus phoenix sp.n.}

Fig. 3

Descrição. Forma oval alongada, convexa em especial na face ventral. Coloração de fundo castanho-escura-avermelhada, pontuação ferrugínea grosseira e densa.

Cabeça, diante dos olhos, de contorno sub-retangular, mais larga do que longa, declivosa. Margens externas das jugas sinuosas, convergentes no ápice e sobrepostas na frente do clípeo. Tubérculos anteníferos encobertos pelas jugas, não visíveis em vista dorsal. Rostro ultrapassando, o limite anterior do terceiro segmento abdominal; primeiro artículo com cerca da metade basal contida nas búculas atingindo, o 1/3 anterior do prosterno; segundo artículo comprimido lateralmente, mal alcançando as mesocoxas; terceiro e quarto artículos comprimidos dorso-ventralmente, o terceiro mal alcançando as metacoxas.

Pronoto. Margem anterior rasamente convexa, dentículos nos ângulos ântero-laterais em pontas rombas; $2 / 3$ anteriores acentuadamente em declive; grosseiro e densamente pontuado, coloração de fundo castanho-escura-avermelhada, com 
pontuações grandes, ferrugíneas, freqüentemente confluentes nas margens ânterolaterais. Ângulos umerais rombos projetados lateralmente formando um ângulo inferior a $90^{\circ}$. Escutelo: coloração e pontuações como no pronoto; margens laterais sub-retilíneas, disco elevado, ápice arredondado, margens laterais sutilmente refletidas; fóveas dos ângulos basais obsoletas. Hemiélitros: coloração castanha com manchas amplas avermelhadas no endocório, pontuações ferrugíneas do cório mais confluentes que no pronoto e escutelo. Ápice do cório alcançando o meio do sétimo segmento do conexivo. Membrana mal ultrapassando o ápice do abdome. Pernas amarelo-escuras com densa pontuações negras, grosseiras, nos fêmures e tíbias. Conexivo estreitamente exposto, coloração castanho-escura-avermelhada e pontuações similares às do cório, borda preta interrompida próxima ao ângulo pósterolateral de cada segmento. Abdome castanho escuro-avermelhado na face ventral e com pontuações negras, mais finas e concentradas nos terços laterais; $1 / 3$ médio com pontuações mais grosseiras e esparsas. Espiráculos negros; tricobótrios localizados externamente à linha imaginária que tangencia os espiráculos.

Medidas. Comprimento da cabeça 2,37; largura da cabeça 3,85; comprimento diante dos olhos 1,14; distância interocular 2,13; comprimento dos artículos antenais I 0,73 , II 1,55, III 1,64, IV 2,46, V 2,29; comprimento do pronoto 3,77; largura do pronoto 9,75 ; comprimento do escutelo 6,72 ; largura do escutelo 6,15 ; largura abdominal 9,10; comprimento do cório 9,18.

Genitália. Margem posterior do sétimo urosternito (VII) sinuosa sobre os laterotergitos 8 (La8) e gonocoxitos 8 (Gc8). Gonocoxitos 8 mais largos do que longos, com bordo posterior uniformemente convexo, projetado sobre os laterotergitos 9 (La9). Laterotergitos 8 destituídos de espiráculos, bordo posterior moderadamente convexo. Laterotergitos 9 recobrindo o segmento X, bordo posterior subtruncado, margens laterais internas quase retiliníneas, adjacentes medianamente, prega submarginal quase imperceptível. Genitália interna não dissecada por tratar-se de apenas um exemplar.

Material-tipo. Holótipo fêmea. Costa RicA, Prov. Alaju: Est. San. Ramón Oeste, 620m, 3-19.VI.1994, F. Quesada leg., (LN318100-381900 $=2817$ n $^{\circ}$ INBio CRI001776381)

\section{Ablaptus brevirostrum Rolston, 1988}

Fig. 4

Ablaptus brevirostrum Rolston,1988: 286-288, figs 3-7; Becker \& Grazia, 1989: 63-64, figs 2, 6, 10, 17 , 20, 23, 26.

Genitália da fêmea. Gonocoxitos 8 (Gc8) amplos, quase tão longo quanto largos, subtrapezoidais, bordo posterior obtusamente angulado. Laterotergitos 8 (La8) destituídos de espiráculos, bordos posteriores uniformemente convexos. Laterotergitos 9 (La9) quase semiesféricos recobrindo o segmento X, com margens laterais internas levemente sobrepostas, destituídos de pregas submarginais; estreita faixa apical negra.

Material examinado. Parátipo fêmea, com as seguintes etiquetas: PANAMÁ, B.C.I., 29.V.1957, F. Schrader, A1 18/ Ablaptus brevirostrus H. Ruckes ALLOTYPE/ PARATYPE Ablaptus brevirostrum Rolston [det.] (American Museum of Natural History). 
Comentários. Embora se assemelhem no aspecto geral, as espécies novas $A$. costaricensis e $A$. phoenix distinguem-se de $A$. brevirostrum pela ausência de fóveas negras nos ângulos basais do escutelo e pelo comprimento do rostro nitidamente ultrapassando a base do abdome. As placas genitais, principalmente a forma e tamanho dos gonocoxitos 8 e laterotergitos 9 , ilustradas neste trabalho, permitem separar facilmente estas espécies entre si e das demais espécies do gênero ilustradas em BECKER \& GRAZIA (1989) (A. bolivianus, A. simillimus e A. tavakiliani) e BECKER \& GRAZIA (1997) (A. varicornis). A fêmea de A. amazonus é ainda desconhecida. RoLSTON (1988) em sua ilustração da genitália do parátipo de $A$. brevirostrum não foi fiel, principalmente na forma dos gonocoxitos 8 o que induziu a um erro na chave para separar as fêmeas de Ablaptus proposta por BECKER \& GrAZIA (1989). A chave a seguir corrige esta falha e inclui as novas espécies, além de $A$. varicornis.

\section{Chave para as espécies de Ablaptus (fêmeas)}

1. Bordo posterior dos gonocoxitos 8 uniformemente convexo (Fig. 3) ... phoenix - Bordo posterior dos gonocoxitos 8 não uniformemente convexo (Figs 2 e 4 ) . . .2

2. Laterotergitos 9 , ultrapassando os bordos posteriores dos laterotergitos $8 \mathrm{em}$ mais da metade de seu comprimento . . . . . . . . . . . . . . . simillimus

- Laterotergitos 9, igualando ou pouco ultrapassando os bordos posteriores dos

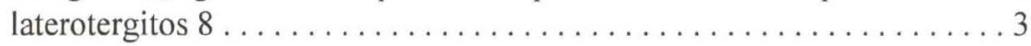

3. Gonocoxitos 8 mais largos do que longos, bordos posteriores côncavos sobre os

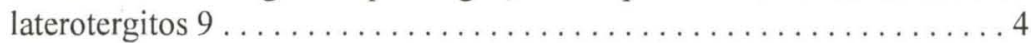

- Gonocoxitos 8 mais longos do que largos ou pelo menos tão longos no meio quanto largos, bordos posteriores sub-retilíneos ou em "V" sobre os laterotergitos

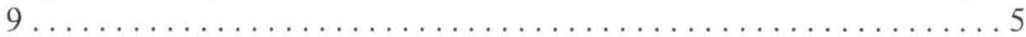

4. Ângulos póstero-laterais dos gonocoxitos 8 mais projetados posteriormente que os ângulos suturais; bordos posteriores dos laterotergitos 8 uniformemente convexos ................................ tavakiliani

- Ângulos póstero-laterais e ângulos suturais dos gonocoxitos 8 situados praticamente no mesmo nível; bordos posteriores dos laterotergitos 8 subretilíneos varicornis

5. Laterotergitos 9 adjacentes ou sobrepostos medianamente, encobrindo o segmento $\mathrm{X}$; bordos laterais externos dos gonocoxitos 8 retilíneos ou convexos . 6

- Laterotergitos 9 afastados entre si, deixando o segmento X parcialmente visível; bordos laterais externos dos gonocoxitos 8 sinuosos ......... bolivianus

6. Laterotergitos 9 adjacentes medianamente; bordos laterais internos dotados de pregas submarginais nos $2 / 3$ anteriores (Fig. 2) .......... costaricensis

- Laterotergitos 9 levemente sobrepostos medianamente; bordos laterais internos destituídos de pregas submarginais (Fig. 4) ............ brevirostrum 


\section{REFERÊNCIAS BIBLIOGRÁFICAS}

BeCKer, M. \& J. Grazia. 1989. Novas contribuições ao gênero Ablaptus Stål, 1864 (Heteroptera, Pentatomidae, Discocephalinae). Mem. Inst. Oswaldo Cruz 84 (Supl. 4): 57-68.

BECKER, M. \& J. GRAZIA. 1997. A new combination and a new synonymy in Discocephalini (Heteroptera, Pentatomidae). Revta bras. Zool. 14 (2): 319-321.

Rolston, L.H. 1988. The genus Ablaptus Stål (Pentatomidae: Discocephalinae: Discocephalini). Jour.

N.Y. Ent. Soc. 96 (3): 284-290.

STÁL, C. 1864. Hemiptera nonnula nova vel minus cognita. Ann. Soc. ent. Fr. (4): 47-68.

WALKER, F. 1867. Catalogue of the specimens of heteropterous Hemiptera in the collection of the

British Museum. London, Bristish Museum, Part 2, p. 241-418.

Recebido em 03.1.2000; aceito em 13.XII.2000. 